Житин Руслан Магометович, Сабетова Марина Викторовна, Патрина Людмила Николаевна ЧАСТНАЯ ИНИЦИАТИВА КАК ФАКТОР СОЗДАНИЯ НАРЫШКИНСКОЙ НАРОДНОЙ ЧИТАЛЬНИ

\title{
ВГ. ТАМБОВЕ
}

В статье рассмотрены вопросы создания в г. Тамбове Нарышкинской народной читальни. Показано, что появление новой библиотечной инфраструктуры повышало эффективность просвещения различных групп горожан. Актуальность исследования определяется важной ролью нарышкинского учреждения в культурном развитии населения г. Тамбова, в становлении новых форм читательской культуры. Научная новизна заключается в комплексном изучении места частной благотворительности в системе библиотечного дела региона, выявлении качественно-количественного вклада отдельных жертвователей в фонды Народной читальни.

Адрес статьи: www.gramota.net/materials/9/2019/11/6.html

\section{Источник}

\section{Манускрипт}

Тамбов: Грамота, 2019. Том 12. Выпуск 11. С. 34-38. ISSN 2618-9690.

Адрес журнала: www.gramota.net/editions/9.html

Содержание данного номера журнала: www.gramota.net/materials/9/2019/11/

\section{() Издательство "Грамота"}

Информация о возможности публикации статей в журнале размещена на Интернет сайте издательства: www.gramota.net Вопросы, связанные с публикациями научных материалов, редакция просит направлять на адрес: hist@gramota.net 


\title{
STATE RESETTLEMENT POLICY IN THE RUSSIAN FAR EAST AT THE END OF THE XIX - THE BEGINNING OF THE XXI CENTURY: SOCIAL AND HISTORICAL ASPECT
}

\author{
Vasil'chenko Oleg Alekseevich, Doctor in History, Associate Professor \\ Amur State University of Humanities and Pedagogy, Komsomolsk-on-Amur \\ sfknagtu@mail.ru
}

\begin{abstract}
The article shows the role of the state resettlement policy to protect Russia's national interests in the Far East during 150-year history. A comparative analysis of the resettlement policy in the pre-revolutionary and Soviet period has allowed the author to identify continuity, to reveal its common and distinctive features in the social and historical aspect. The paper shows current changes in Russia's resettlement policy and their negative influence on the demographic situation and the formation of the Far East residential population.
\end{abstract}

Key words and phrases: history; settlement; The Far East; The Russian Empire; The USSR; The Russian Federation; population; analysis; state policy.

УДК 93

https://doi.org/10.30853/manuscript.2019.11.6

Дата поступления рукописи: 07.10.2019

В статье рассмотрены вопросы создания в г. Тамбове Нарышкинской народной читальни. Показано, что появление новой библиотечной инфраструктуры повышало эффективность просвещеени различных групп горожан. Актуальность исследования определяется важной ролью нарыикинского учреждения в культурном развитии населения 2. Тамбова, в становлении новых форм читательской культуры. Научная новизна заключается в комплексном изучении места частной благотворительности в системе библиотечного дела региона, выявлении качественно-количественного вклада отдельных жертвователей в фонды Народной читальни.

Ключевые слова и фразы: Э. Д. Нарышкин; книжная культура; Нарышкинская народная читальня; личные библиотеки; народные чтения.

Житин Руслан Магометович, к.и.н.

Тамбовский государственный университет имени Г. Р. Державина

istorik08@mail.ru

Сабетова Марина Викторовна

Патрина Людмила Николаевна

Тамбовская областная универсальная научная библиотека имени А. С. Пушкина

sabetova@tambovlib.ru; lnp@tambovlib.ru

\section{ЧАСТНАЯ ИНИЦИАТИВА КАК ФАКТОР СОЗДАНИЯ НАРЫШКИНСКОЙ НАРОДНОЙ ЧИТАЛЬНИ В Г. ТАМБОВЕ}

Работа выполнена при финансовой поддержке РФФИ (грант № 19-09-00484).

Одной из важнейших черт развития библиотечного дела Тамбовской губернии во второй половине XIX века является развитие сети публичных библиотек, большая часть которых появилась благодаря частной инициативе. С одной стороны, этому способствовали демократизация общественной жизни и рост интереса к печатному слову среди широких масс населения, с другой - существенную роль в данном процессе сыграли личные пожертвования крупнейших тамбовских владельцев, отдававших свои книжные собрания на обустройство новых учреждений.

Изучение структуры частных книжных пожертвований в публичные библиотеки позволяет сделать выводы о специфике собраний книголюбов-благотворителей, особенностях их читательской культуры. Целью данной статьи является анализ истории создания и характера деятельности Нарышкинской народной читальни - крупнейшего библиотечного учреждения Тамбовской губернии конца XIX - начала XX века. В задачи работы входят анализ особенностей комплектования книжных фондов, их отраслевого разнообразия, выявление специфики работы основных подразделений организации - Народной читальни и Особой библиотеки. Актуальность исследования определяется высоким значением библиотечных учреждений в системе дореволюционного образования, их ролью в формировании культурного пространства региона. Научная новизна заключается в комплексном изучении процесса развития частного библиотечного дела в региональном аспекте, углублении знаний об истории провинциальной книжной культуры.

Практически все тамбовские библиотеки имели своих благотворителей, пожертвования которых в большинстве случаев играли решающую роль в комплектовании их фондов. В 1891 г. была открыта Усманская публичная библиотека. Ее основу составило владельческое собрание А. М. Сибиряковой, передавшей в учреждение практически всю личную библиотеку (1433 тома) [3, с. 126]. Не менее примечателен дар Сафронова, пожертвовавшего более 1500 книг в Козловскую народную библиотеку [5, с. 3]. Многократно выросший фонд позволил 
преобразовать статус библиотеки из народной в публичную. Схожую историю имела и Моршанская библиотека, которая была преобразована в публичную благодаря личному собранию П. И. Киселева [4, с. 129]. Перечисленные учреждения стали важными культурно-просветительскими центрами своих уездов, популяризируя книгу и чтение среди самых широких масс населения.

Наиболее масштабный проект организации частной библиотеки в губернском центре связан с именем знаменитого мецената Э. Д. Нарышкина. В 1890 г. по его инициативе в Тамбове начинают проходить первые народные чтения [2, с. 210]. Они должны были способствовать просвещению народа, приобщению населения к печатному слову и грамотности. В то время это был достаточно эффективный формат развития внешкольного образования, призванный восполнить дефицит народных школ и вырвать народ из «тины... невежества, темноты и грубости» [7, с. 1026]. Часто подобные мероприятия сопровождались хоровыми выступлениями, игрой оркестра, что привлекало к ним множество народа.

В первый год проведения чтений стал очевиден успех нового дела. На сеансы приходило до 500 человек, что уже не соответствовало возможностям зала при мужской гимназии $[1$, с. 5]. Огромный интерес к мероприятиям потребовал строительства отдельного здания, а также придания инициативе соответствующего организационного статуса. В 1893 г. Э. Д. Нарышкиным был подготовлен устав Общества по устройству народных чтений, не имевший аналогов в истории страны [16]. Документ подтверждал официальный характер учреждения и закреплял равные возможности для просвещения на территории всей губернии. Для придания делу финансовой самодостаточности Э. Д. Нарышкин выделил неприкосновенный капитал в 200 тыс. рублей [1, с. 11].

Инициатива нашла благодарный отклик у народных масс. «Спрос на книги народных библиотек, где ведутся чтения с картинами, - писал заведующий чтениями Покровской земской школы Лебедянского уезда, сильно увеличился, и особенно радостно видеть то, что произведения Пушкина, Лермонтова, Гоголя начинают интересовать слушателей более осознанно» [13, с. 28].

Если народные чтения должны были способствовать поддержке интереса к внешкольному образованию, то строительство помещений для их проведения должно было удовлетворить читательские запросы целевой аудитории. В 1892 г. в губернском центре началось возведение нового здания для народных чтений. «Строю этот дом, - говорил Э. Д. Нарышкин при закладке здания Общества, - для ваших собратьев, для серого народа, который я люблю. Для вас... ваши трудовые деньги желаю я сберечь; вместо того, чтобы тратить праздничное время на непозволительные и убыточные развлечения, приходите в это здание и поучайтесь тому, что вам будут читать здесь» $[2$, с. 221].

По разработанному проекту здание должно было быть двухэтажным, с обширным залом для публичных мероприятий и комплексом библиотечных учреждений, включавших Особую и Выдачную библиотеки, Народную читальню. В общей сложности на строительство всей инфраструктуры Э. Д. Нарышкин затратил более 100 тыс. рублей [1, с. 7].

Торжественное открытие здания для народных чтений состоялось 1 июля 1894 г. Это были важнейшее событие в культурной жизни Тамбовской губернии и важная веха в социокультурной модернизации края. Библиотеки, размещенные на первом этаже, давали возможность самым широким слоям населения пользоваться литературой как на дому, так и в читальных залах. Кроме того, в обширных помещениях могли проходить комплексные литературно-музыкальные мероприятия с публичным прочтением книг и выступлениями оркестра.

Центральное место в структуре нового учреждения отводилось Народной читальне с Отделением для выдачи книг на дом (Выдачная библиотека). По сути, это был прообраз современных общедоступных библиотек. Читатели могли пользоваться базовой литературой в прекрасно оборудованном читальном зале, в случае необходимости имели возможность взять книги для домашнего использования. Последнее имело принципиальное значение, ведь «многие жители города или по недостатку свободного времени или по отдаленности места жительства от их читальни при искреннем желании не могут посещать ее». Вариант с самостоятельным выбором книги или «заказом при посредничестве знакомых» многие пользователи видели «удобным и возможным» [2, с. 228].

Свой фонд Выдачная библиотека и Народная читальня формировали постепенно на основании частных пожертвований и централизованной закупки литературы. Согласно отчетам общества, к 1903 г. в Читальне насчитывалось 2941 книга и журнал на общую сумму 6900 рублей. Фонд Выдачной библиотеки был гораздо скромнее - 1831 (на 2000 рублей), что отражало общий характер деятельности этого учреждения (см. Рис. 1).

Всю имеющуюся литературу можно условно разделить на пять разделов. Универсальность этого собрания позволяла удовлетворять запросы любых групп пользователей. Доминирующей категорией книг в библиотеках являлась художественная литература, занимавшая в общей сложности до $45 \%$ фонда. Остальные разделы занимали примерно равные доли в общей структуре книгохранения.

Вполне демократичный способ заказа изданий сочетался с безвозмездным вариантом использования фонда. Отсутствие платы за книги выгодно отличало созданное учреждение от Тамбовской публичной библиотеки, получавшей с каждого читателя до 15 рублей за работу в читальном зале и 30 рублей (при залоге 35 рублей) при выдаче книг на дом [8, с. 7]. В среднем Читальный зал и Выдачный отдел ежедневно посещали более 100 человек. Всего же в 1894-1900 гг. библиотеку посетило более 170 тыс. человек [1, с. 20].

Неудивительно, что популярность нарышкинских учреждений быстро затмила славу Тамбовской публичной библиотеки (ТПБ), не располагавшей столь солидными возможностями и материально-технической базой. В начале $\mathrm{XX}$ века ТПБ окончательно приходит в упадок и фактически прекращает свою деятельность. Вопрос о передаче библиотеки на баланс города или земских учреждений остается нерешенным из-за опасений возможных претензий ее акционеров. Только в начале 1917 г. тяжба с акционерами успешно завершилась и библиотека стала частью Тамбовской ученой архивной комиссии. 


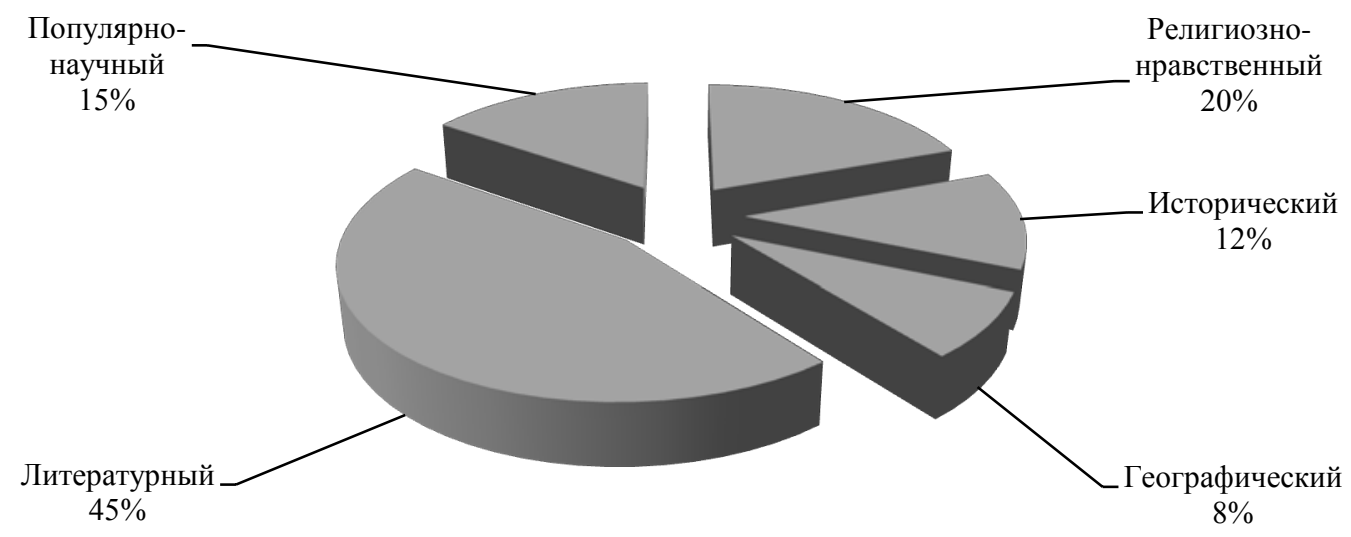

Рисунок 1. Отраслевая принадлежность литературы в фонде Выдачной библиотеки и Народной читальни [2, с. 228]

В 1897 г. построенное здание народных чтений осматривал великий князь Сергей Александрович. Он отметил качество фонда и созданные условия для работы в библиотеке. «Буду рад сообщить Эммануилу Дмитриевичу, - заключал высокий гость, - что, осмотрев его учреждения, нашел их в отличном порядке» [2, с. 221].

В отличие от общедоступной Нарышкинской читальни Особая библиотека действовала на основе специальных правил, утвержденных министром народного просвещения в 1893 г. Этот документ допускал комплектование фондов подобных учреждений запрещенной, не прошедшей цензурный контроль литературой. Однако использовать ее могли только особо благонадежные лица для проведения своих научных исследований. За обеспечением порядка работы с книгами следил библиотекарь, лично ответственный за соблюдение установленных правил.

Для первых читателей Особая библиотека была открыта 2 января 1894 г. [Там же, с. 231]. Значительную помощь при ее открытии оказал тайный советник, бывший попечитель Харьковского учебного округа И. П. Хрущев, активно лоббировавший идею открытия подобного учреждения в Тамбовской губернии.

В основу фонда вновь созданной библиотеки были положены частные коллекции книг из собраний знаменитого российского ученого, библиографа, члена Российской академии наук Д. В. Поленова (1806-1878) и тамбовского краеведа, земского деятеля Л. В. Воейкова (1818-1885).

История появления указанных коллекций в Тамбове - яркая страница в истории благотворительности российского дворянства. Родовая библиотека семьи Поленовых собиралась несколько десятилетий. После смерти Дмитрия Васильевича Поленова его наследник Василий Дмитриевич перевез семейные книги в родовое поместье своей жены - имение Ольшанка Тамбовской губернии. Здесь состоялось фактическое объединение поленовских собраний с личной библиотекой главы семейства Воейковых - Леонида Васильевича.

Содержание объединенной библиотеки отражает богатые интересы книгодержателей. В фонд вошли редкие собрания сочинений европейских классиков XVII - первой половины XIX века, собрания книг из личной библиотеки Г. Р. Державина, поступившие в коллекцию Поленовых от Бороздиных. Наследие воейковской части составляло несколько тысяч книг по истории и культуре Тамбовской губернии. Кроме того, в фонде присутствовали издания из библиотеки великого князя Николая Александровича, сына Александра III. Историю приобретения этих книг установить не удалось, однако известно, что при осмотре библиотеки великим князем Сергеем Александровичем на эти книги было обращено особое внимание [Там же, с. 221].

В начале 90-х гг. ХІХ века В. Д. Поленову стало известно о строительстве в городе Тамбове здания для народных чтений, и он обратился с письмом к Э. Д. Нарышкину, в котором просил принять в дар городу библиотеки своего отца и дяди. «Будучи в настоящее время владельцем соединённых библиотек покойного отца моего Дмитрия Васильевича Поленова и дядюшки Леонида Алексеевича Воейкова, и зная с одной стороны, что желание моего отца состояло в том, чтобы библиотека его поступила впоследствии на пользу образования где-нибудь в провинции, а с другой стороны, зная заветную мечту моего дядюшки устроить в городе Тамбове общественную библиотеку, и глубоко сочувствуя предпринимаемому Вами чудному делу, я с великой радостью прошу Вас принять от меня в собственность Общества эти две библиотеки в память Дмитрия Васильевича Поленова и Леонида Алексеевича Воейкова» [6, с. 311].

Устроителя Читальни заинтересовало предложение Поленова. В новом учреждении для владельческой коллекции Поленовых и Воейковых была выделена отдельная комната, в которой «люди интеллигентные, желающие не переставать учиться», могли пользоваться подаренными собраниями [Там же, с. 312]. Кроме того, для хранения книг были заказаны специальные книжные полированные шкафы, стулья и столы для посетителей. В 1893 г. администрацией учреждения был создан отдельный каталог книг Д. В. Поленова и Л. А. Воейкова, пожалованных читальне. Согласно данным этого каталога, созданная коллекция насчитывала 3995 экземпляров книг 1891-1904 гг. издания [10, с. 3, 4].

В дальнейшем пополнение библиотеки обеспечивалось благодаря благотворительности частных лиц, передававших свои книги как тайно, так и явно. В числе наиболее крупных - пожертвованная коллекция из 302 книг Алексея Владимировича Вышеславцева (1831-1888), писателя, историка искусств, долгое время 
собиравшего книги по истории культуры Франции, Италии, России [9], и дар семьи Хвощинских, отдавших в читальню более 1200 книг отечественных и европейских классиков XVII - первой половины XIX века [4, с. 48]. Не меньшее значение имела передача «23 наименований русских и зарубежных книг в 44 томах» «госпожи Ушаковой», пополнение учреждения рядом сочинений Б. Н. Чичерина и Д. И. Менделеева [11, с. 31], лично подаренных их авторами [12, с. 17].

Частные коллекции книг тамбовских дворян позволили создать универсальный фонд литературы, прекрасно подходивший для научных занятий по широкому спектру гуманитарных направлений. Структура фонда условно разделялась на 7 отделов: I - богословие; II - история; III - география и статистика; IV - сельское хозяйство, пути сообщения, народное образование; V - словесность и литература; VI - периодические издания; VII - «смесь» [2, с. 232]. В отличие от Читальни и Выдачного отделения, научно-популярного отдела в Особой библиотеке не было. Однако это не сказывалось на ее востребованности. В 1894-1900 гг. в библиотеку записалось более 3,5 тыс. человек, а общее количество посещений превысило 75 тыс. [1, с. 25].

Большой интерес представлял художественный отдел Особой библиотеки, созданный на основе книг из личной библиотеки А. В. Вышеславцева. Здесь хранились более 300 томов по искусству эпохи Возрождения, собрание портретов французских и итальянских художников разного времени. Ценным дополнением книжно-иллюстративной коллекции являлась копия Сикстинской Мадонны из мраморного барельефа «Богоматерь с уснувшим Младенцем на руках» работы знаменитого Донателло. До 60-х гг. XIX века барельеф находился в одном из итальянских монастырей, пока не был приобретен для коллекции Кариницкого в Варшаве. В 1876 г. при распродаже коллекции барельеф был приобретен на средства Вышеславцева, где хранился вплоть до передачи Обществу по устройству народных чтений. В последующем художественный отдел пополнился книгами «Художественные сокровища России», «Третьяковская галерея». В 1903 г. по желанию А. Н. Нарышкиной местную коллекцию пополнили коронационные альбомы Государей Императоров Александра III и Николая II [2, с. 233].

Книги А. В. Вышеславцева имели большое значение для работы нарышкинского учреждения. На основе собранной коллекции в библиотеке занимались студенты тамбовских учебных заведений, краеведы, научные и педагогические сотрудники. Многие посетители интересовались специальными изданиями отдела, в том числе альбомами итальянских художников [14, с. 87], монографиями «Музей Императора Александра III», «Третьяковская галерея», «Художественные сокровища России» [15, с. 31].

Параллельно в читальне был открыт историко-этнографический музей. Коллекция данного музея была создана еще в 1879 г. в память о столетии учреждения губернии. Непосредственное отношение к созданию коллекции и организации музея имел председатель Тамбовской ученой архивной комиссии И. И. Дубасов. Понимая ценность обобщения коллекций предметами по истории Тамбовской губернии, он всячески поддерживал идею создания на базе собранных коллекций отдельной экспозиции. В 1884 г. все собранные предметы были переданы на третий этаж здания Тамбовской публичной библиотеки, однако запустение библиотеки не позволило организовать выставочную деятельность на высоком уровне. Поэтому с обустройством здания Общества для народных чтений собрание переехало на новое место. 16 февраля 1895 г. зал исторического музея был торжественного открыт. Экспозиция была свободна для посещения два раза в неделю - в четверг и воскресенье. К 1903 г. с деятельностью музея смогли ознакомиться более 17 тыс. человек [2, с. 233].

Создание Нарышкинской народной читальни имело большое значение для культуры города Тамбова. Огромную роль в появлении нового библиотечного учреждения играла активизация партнерских отношений уездных земств и частных деятелей, небезучастных к делу благотворительности. В результате за короткий срок в губернском центре удалось создать современное культурное учреждение, институализировать важные направления общественного просвещения. Новая инфраструктура восполняла дефицит площадок для чтения, открывала возможности для образования самых широких групп провинциального населения.

Список источников

1. Десятилетие народных чтений в г. Тамбове. 1890-1900 гг. Тамбов: Губернская земская типография, 1899.40 с.

2. Евгенов В. Очерк десятилетней истории Общества по устройству народных чтений в гор. Тамбове Тамбовской губернии в связи с историей ее образования // Сборник-календарь Тамбовской губернии на 1903 г. Тамбов: Тип. губерн. правления, 1903. С. 210-234.

3. Княжинский Б. П. Усмань в последней четверти XIX века // Княжинский Б. П. Очерки по истории Усманского края: в 2-х ч. Липецк, 1966. Ч. 2. XVIII и XIX столетия. С. 126-147.

4. Медведева О. В. Библиотечное дело как часть историко-культурного наследия Тамбовской губернии (XVIII-XX вв.). Тамбов: Изд-во Першина Р. В., 2007. 237 с.

5. Надеждин. Козловская публичная библиотека // Тамбовские епархиальные ведомости. 1900. № 96 (26 авг.).

6. Некрасов Н. А. Старая Ольшанка - усадьба Воейковых. Тамбов: Музей-усадьба С. В. Рахманинова «Ивановка», $2018.328 \mathrm{c}$.

7. Общее народное пение, народные певческие курсы // Тамбовские епархиальные ведомости. 1906. № 22. С. 1016-1029.

8. Патрина Л. Н. Деятельность Тамбовской публичной библиотеки // Библиотека: исторический аспект и современное состояние: материалы научно-практической конференции / Тамбовская областная универсальная научная библиотека им. А. С. Пушкина; сост. Л. Н. Патрина. Тамбов, 2005. С. 7-13.

9. Систематический каталог художественно-исторической библиотеки Алексея Владимировича Вышеславцова, переданный Тамбовской народной читальне. СПб., 1895. 25 с.

10. Список книг Дмитрия Васильевича Поленова и Леонида Алексеевича Воейкова, пожертвованных городу Тамбову. СПб.: Тип. А. Катанского и К우 1893. 247 с. 
11. Тамбовское губернское общество по устройству народных чтений. Отчет Общества по устройству народных чтений в городе Тамбове и Тамбовской губернии за 1895/6 год. Тамбов: Скоропечатня губернского земства, 1896. 177 с.

12. Тамбовское губернское общество по устройству народных чтений. Отчет Общества по устройству народных чтений в городе Тамбове и Тамбовской губернии за 1898/9 год. Тамбов: Губернская земская тип., 1900. 194 с.

13. Тамбовское губернское общество по устройству народных чтений. Отчет Общества по устройству народных чтений в городе Тамбове и Тамбовской губернии за 1901 год. Тамбов: Тип. губ. земства, 1902. 221 с.

14. Тамбовское губернское общество по устройству народных чтений. Отчет Общества по устройству народных чтений в городе Тамбове и Тамбовской губернии за 1904 год. Тамбов: Тип. губ. земства, 1906. 215 с.

15. Тамбовское губернское общество по устройству народных чтений. Отчет правления Общества по устройству народных чтений в г. Тамбове и Тамбовской губернии за 1912 г. Тамбов: Тип. губ. земства, 1914. 100 с.

16. Тамбовское губернское общество по устройству народных чтений. Устав Общества по устройству народных чтений в Тамбовской губернии: утв. 18 июня 1899 г. СПб., б. г. 18 с.

\title{
PRIVATE INITIATIVE AS A FACTOR PROMOTING THE OPENING OF NARYSHKIN READING ROOM IN TAMBOV
}

\author{
Zhitin Ruslan Magometovich, Ph. D. in History \\ Derzhavin Tambov State University \\ istorik08@mail.ru \\ Sabetova Marina Viktorovna \\ Patrina Lyudmila Nikolaevna \\ Tambov Regional Universal Scientific Library named after A. S. Pushkin \\ sabetova@tambovlib.ru; lnp@tambovlib.ru
}

The article examines the issues concerning the opening of Naryshkin reading room in Tambov. It is shown that the opening of a new library promoted education of different groups of citizens. Relevance of the study is conditioned by the important role of Naryshkin reading room in the cultural development of Tambov residents, in the development of new forms of reading culture. Scientific originality of the paper involves comprehensive study on the place of private charity in the regional library system, evaluation of qualitative and quantitative contribution of certain donators to replenishing the funds of the people's reading room.

Key words and phrases: I. D. Naryshkin; reading culture; Naryshkin reading room; private libraries; public readings.

УДК 93/94; 929.522.1

https://doi.org/10.30853/manuscript.2019.11.7

Дата поступления рукописи: 16.07.2019

В статье проводится генеалогическое исследование семьи художнка-карикатуриста П. Е. Щербова. Источниковую базу исследования составляют архивные материалы России и Финляндии, документы из музейного собрания и периодчческая печать. Впервые в отечественной историографии выявлены предки Щербова, изучены их биографии, достижения и сочиальный статус. Делается вывод о том, что семья художника благодаря своим способностям прошла весь путь от низших сословий и добилась положения и значительного благосостояния, а также в результате анализа национальность художника идентифицирована как русская.

Ключевые слова и фpaзы: П. Е. Щербов; график; карикатура XIX - начала XX века; дворяне, купцы и чиновники Санкт-Петербурга; заводчики Демидовы; Вильманстранд; домовладельцы Васильевского острова.

\section{Журавлева Александра Геннадьевна}

Историко-мемориальньій музей-усадьба П. Е. Щербова, г. Гатчина

zuccolinaz@gmail.com

\section{РОДОСЛОВНАЯ ХУДОЖНИКА П. Е. ЩЕРБОВА}

Павел Егорович Щербов (1866-1938) - богатый русский дворянин, крупный художник-карикатурист, который является уникальным и оригинальным явлением в искусстве. Вопрос его этнического происхождения никогда не ставился под сомнение, хотя изысканий в данной области не было. Также до сих пор остается открытым вопрос, как его предки получили дворянский титул и обзавелись солидным состоянием. Данные вопросы не попадали в сферу интересов исследователей, а генеалогических исследований семьи П. Е. Щербова не проводилось.

Научных работ, посвященных художнику, крайне мало, и главной их темой является анализ творчества Щербова. Еще при жизни художника его приятель В. Ф. Боцяновский проводил с ним беседы, чтобы написать о нем книгу, но она так и не была издана. На данный момент сохранились лишь его черновики, где отсутствуют какие-либо сведения о предках художника [16]. В книге Г. Ю. Стернина «Очерки русской сатирической графики» полностью опущены биографические сведения, и приводится лишь краткая оценка его художественной деятельности [13]. Самым обширным исследованием является монография «Павел Егорович Щербов» профессора и доктора искусствоведения А. Н. Савинова, вышедшая 50 лет назад. В монографии в основном проводится 